\title{
Posterior Fractures of the Tibial Plateau: Are We on the Right Track?
}

\section{Robinson Esteves Santos Pires ${ }^{1 *}$, Egidio Oliveira Santana Junior ${ }^{2}$ and Nathan de Oliveira Moreira dos Santos ${ }^{2}$}

${ }^{1}$ Federal University of Minas Gerais, Belo Horizonte, Minas Gerais, Brazil

${ }^{2}$ Felicio Rocho Hospital, Belo Horizonte, Minas Gerais, Brazil

Posterior fractures represent less than $10 \%$ of the tibial plateau fracture total. They frequently occur due to high energy trauma, but osteopenic patients can also present this fracture pattern related to low energy events.

Posterior element fracture management has changed significantly throughout the last decade. Several classification systems, posterior approaches, and technical tricks were developed for outcome treatment improvement.

Although Schatzker classification for tibial plateau fractures is a system used worldwide, it only considers the X-Ray in anteroposterior view, lacking information about fracture location on the sagittal plane [1].

Moore attempted to create a classification system that also considers the X-Ray lateral view [2].

Recently, Luo developed the three-column classification system based on the CT-Scan axial view. Luo classification is a helpful method concerning the correct approach choice as it is based on fracture location [3]

Anterolateral and anteromedial approaches are mostly unsuitable for posterior element reduction and fixation, as they lead to poor functional outcomes.

Tscherne and Lobenhoffer first described the posteromedial approach for Moore type I split fractures, which allows direct fracture reduction and rigid fixation with an antigliding plate [4].

Fakler et al. presented their first results and a step-by-step surgical procedure for applying Lobenhoffer technique [5].

However, the posteromedial approach is frequently inadequate to treat posterior bicondilar and isolated posterolateral fractures.

Carlson described the double posteromedial and posterolateral approaches for posterior bicondilar fractures. The author highlighted the need for careful fibular nerve handling to prevent neuropraxia [6]. Bhattacharyya et al. proposed a unique posterior approach to fix this fracture pattern [7].

Although these approaches have contributed to better posterior fracture management, some fracture patterns such as associated anterior and posterior fractures remain a challenge for the orthopaedic surgeon.

Patient positioning, small posterolateral window, and fibular head are obstacles for fracture reduction and plate placement.

Solomon et al. presented his functional outcomes using fibular osteotomy for better posterolateral exposure [8]. This approach also allows fixing complex anterolateral and posterolateral fractures as it uses double plating or as described by Bermudez et al., just a single horizontal rafting plate [9]. Fibular neck nonunion and fibular common neuropraxia are potential complications related to this procedure. However, the authors described absence of complications related to the osteotomy. Rigid fixation preserving the regional blood supply and careful nerve handling are essential to avoid such complications.
Yu et al. described the partial fibular head ostectomy, preserving lateral collateral ligament to prevent knee instability [10].

Frosch et al. developed a new approach without fibular osteotomy. In a laterally positioned patient, a $15 \mathrm{~cm}$ skin incision starts $3 \mathrm{~cm}$ above the joint line and follows the fibula distally, allowing posterolateral and anterolateral windows for fracture reduction and fixation [11].

Although posterior fracture management has been improving, this fracture pattern remains a challenge for the orthopaedic trauma surgeon. The possibility of a catastrophic neurovascular injury during the procedure, the difficult surgical technique due to inadequate posterolateral exposure, and the need of combined approaches for complex fractures are some of the potential obstacles to overcome.

In high energy trauma, a two stage procedure applying a spanning external fixation until the wrinkle sign appears is recommended to prevent soft tissue complications.

In summary, X-ray in anteroposterior, lateral, and oblique views, as well as the CT-Scan are essential for the operative planning.

Complex fracture patterns mostly require multiple approaches. In bicondilar fractures, the medial fragment is generally a unique posteromedial split fracture, and starting the fixation on this fragment is recommended. Careful soft tissue handling, including the fibular nerve identification and isolation during the entire procedure, is mandatory. Anatomical reduction with rigid fixation achieving a stable joint and early movement complete the requirements to decrease complication rates related to posterior fractures of the tibial plateau.

Although current results applying these promising techniques can put us on the right track concerning posterior fracture management, long term follow-up is necessary to evaluate functional outcomes and complication rates related these encouraging procedures.

\section{References}

1. Hohl M (1991) Part I: fractures of the proximal tibia and fibula. In: Rockwood C Green D, Bucholz R. Fractures in adults. (3rdedn), JB Lippincott, Philadelphia, USA.

2. Moore TM, Harvey JP Jr (1974) Roentgenographic measurement of tibialplateau depression due to fracture. J Bone Joint Surg Am 56: 155-160.

3. Zhu Y, Yang G, Luo CF, Smith WR, Hu CF, et al. (2012) Computed tomographybased Three-Column Classification in tibial plateau fractures: introduction of its utility and assessment of its reproducibility. J Trauma Acute Care Surg 73 731-737.

*Corresponding author: Robinson Esteves Santos Pires, Federa University of Minas Gerais, Belo Horizonte, Minas Gerais, Brazil, E-mail: robinsonesteves@ig.com.br

Received April 19, 2013; Accepted April 22, 2013; Published April 24, 2013

Citation: Pires RES, Junior EOS, dos Santos NOM (2013) Posterior Fractures of the Tibial Plateau: Are We on the Right Track? J Trauma Treat 2: e112. doi:10.4172/2167-1222.1000e112

Copyright: (c) 2013 Pires RES, et al. This is an open-access article distributed under the terms of the Creative Commons Attribution License, which permits unrestricted use, distribution, and reproduction in any medium, provided the original author and source are credited. 
Citation: Pires RES, Junior EOS, dos Santos NOM (2013) Posterior Fractures of the Tibial Plateau: Are We on the Right Track? J Trauma Treat 2: e112. doi:10.4172/2167-1222.1000e112

Page 2 of 2

4. Tscherne $H$, Lobenhoffer $P$ (1993) Tibial plateau fractures. Management and expected results. Clin Orthop Relat Res 87-100.

5. Fakler JK, Ryzewicz M, Hartshorn C, Morgan SJ, Stahel PF, et al. (2007) Optimizing the management of Moore type I postero-medial split fracture dislocations of the tibial head: description of the Lobenhoffer approach. $J$ Orthop Trauma 21: 330-336.

6. Carlson DA (2005) Posterior bicondylar tibial plateau fractures. J Orthop Trauma 19: 73-78.

7. Bhattacharyya T, McCarty LP 3rd, Harris MB, Morrison SM, Wixted JJ, et al (2005) The posterior shearing tibial plateau fracture: treatment and results via a posterior approach. J Orthop Trauma 19: 305-310.

8. Solomon LB, Stevenson AW, Baird RP, Pohl AP (2010) Posterolateral transfibular approach to tibial plateau fractures: technique, results, and rationale. J Orthop Trauma 24: 505-514.

9. Bermúdez CA, Ziran BH, Barrette-Grischow MK (2008) Use of horizontal rafting plates for posterior elements of complex tibial plateau fractures: description and case reports. J Trauma 65: 1162-1167.

10. Yu B, Han K, Zhan C, Zhang C, Ma H, et al. (2010) Fibular head osteotomy: a new approach for the treatment of lateral or posterolateral tibial plateau fractures. Knee 17: 313-318.

11. Frosch KH, Balcarek $P$, Walde $T$, Stürmer KM (2010) A new posterolatera approach without fibula osteotomy for the treatment of tibial plateau fractures. J Orthop Trauma 24: 515-520. 